\title{
Engaging Students in a Large Enrollment Physics Class Using an Academically Focused Social Media Platform
}

\author{
A. Gavrin, Indiana University - Purdue University Indianapolis, Indianapolis, IN \\ Rebecca Lindell, Purdue University, West Lafayette, IN
}

There are many reasons for an instructor to consider using social media, particularly in a large introductory course. Improved communications can lessen the sense of isolation some students feel in large classes, and students may be more likely to respond to faculty announcements in a form that is familiar and comfortable. Furthermore, many students currently establish social media sites for their classes, without the knowledge or participation of their instructors. Such "shadow" sites can be useful, but they can also become distributors of misinformation, or venues for inappropriate or disruptive discussions. CourseNetworking (CN) is a social media platform designed for the academic environment. It combines many features common among Learning Management Systems (LMSs) with an interface that looks and feels more like Facebook than a typical academic system. We have recently begun using $\mathrm{CN}$ as a means to engage students in an introductory calculus-based mechanics class, with enrollments of 150-200 students per semester. This article presents basic features of $\mathrm{CN}$, and details our initial experiences and observations.

\section{Why social media? The dangers of inadequate communications}

Weak communications among faculty and students can exacerbate many of the problems that affect large classes. Students may feel "lost" in the large lecture environment. This has been noted in a variety of studies over many years. ${ }^{1,2}$ It is important to address this issue, particularly with respect to persistence in STEM majors of first-generation college students, ${ }^{3}$ and members of underrepresented groups. ${ }^{2}$ Such students' mastery of the material, sense of inclusion in the university community, and development of identity as a future professional may all be adversely affected by a lack of communication. In turn, faculty members become disappointed with their students' learning outcomes, and the diversity of the physics (and engineering) community suffers. To avoid these difficulties, it is essential that students be able to communicate with the instructor(s), and that they be able to communicate with one another.

In recent years, social media have become a nearly ubiquitous form of communications among college students. ${ }^{4}$ The import of this has been debated, with some studies showing that social media use is a serious distraction for students, ${ }^{5}$ while other studies have shown that it is not social media per se, but multitasking that is problematic. ${ }^{6}$ Other instructors have reported positive results in trial uses of Facebook as a collaboration tool for classes. ${ }^{7}$ With this in mind, we began our experiment with $\mathrm{CN}$.

\section{CourseNetworking characteristics}

CourseNetworking (CN) is a cloud-based application that is free to both faculty and students. A faculty member may set up a site for each course, which will include tools for distributing a syllabus, maintaining a grade book, exchanging files with students, etc. However, unlike a traditional LMS, these functions are intentionally secondary in the appearance of the site.

Figure 1 shows a portion of the $\mathrm{CN}$ site for a calculus-based mechanics course taught by one of us (AG). ${ }^{8}$ We will provide details, but would like to draw immediate attention to the student post shown in area 5 . The post includes the original poster's text (organizing a study group) several "reflections," the number of "likes" received at each comment level, and the box for another user to add an additional reflection. This "front and center" location for student contributions sets $\mathrm{CN}$ apart from other tools, e.g., the discussion boards embedded in some LMSs.

CN is FERPA and ADA compliant, and includes both LTI $^{9}$ and SCORM ${ }^{10}$ interoperability standards, allowing it to work in concert with other academic systems. CN supports all com-

This is the author's manuscript of the article published in final edited form as:

Gavrin, A., \& Lindell, R. (2017). Engaging Students in a Large-Enrollment Physics Class Using an Academically Focused Social Media Platform. The Physics Teacher, 55, 176-179. http://dx.doi.org/10.1119/1.4976664 
mon platforms and browsers, and $\mathrm{CN}$ apps are available for both IOS and Android. Other features are described on the $\mathrm{CN}$ website. ${ }^{11} \mathrm{We}$ have not used every available tool in $\mathrm{CN}$, nor can we give detailed accounts of all the tools we have used in this article. However, we have found several to be particularly useful. We will highlight those, and provide a general overview.

\section{Overview of CourseNetworking}

In Fig. 1, area 1 occupies the upper edge of the display. This area provides access to tools that act at the $\mathrm{CN}$ system level. These include an email tool, access to $\mathrm{CN}$ help, and a menu that allows users to select among their course sites. Just below, area 2 provides tools for creating new content at the course level, including tasks, posts, and polls, which we describe later. Interested readers can find more details, including "how to" videos, on the CN YouTube channel. ${ }^{12}$

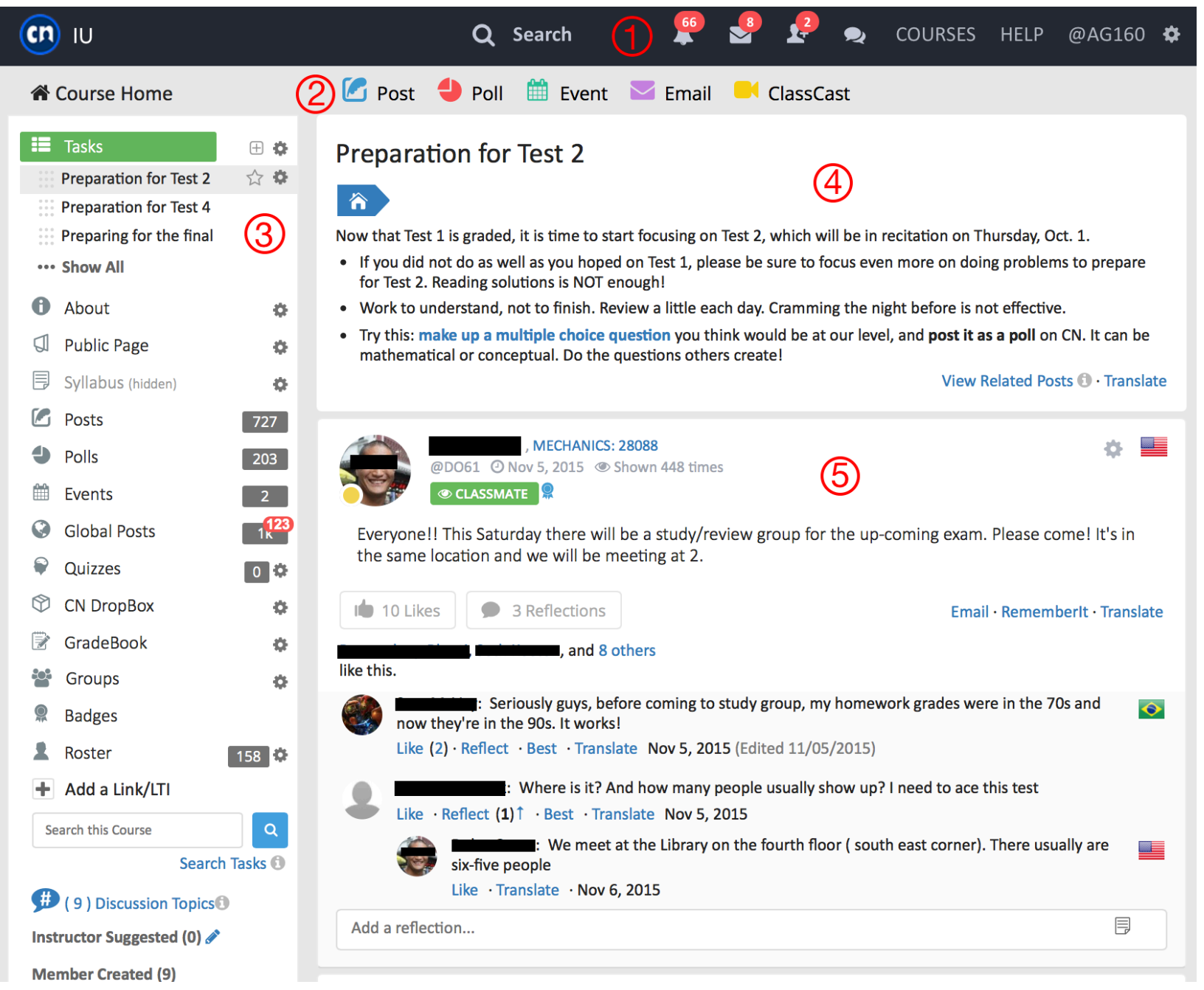

Fig. 1. Screen capture from the author's fall 2015 implementation of CourseNetworking. The marked areas include (1) system-wide tools; (2) content creation tools; (3) instructor tools, LMS features and site statistics; (4) The task area; (5) posts, polls, and other content. Not shown are tools for sorting and filtering, and the scroll bars. 
Area 3, on the left, includes tools associated with creation and selection of "tasks," statistics for the course, and several tools typical of LMSs, such as a grade book and roster. There is also a search tool that allows users to search the course site for particular users, phrases, etc.

The top area on the right (area 4) is the task area. Tasks are created by the instructor(s) and may be used to structure the course according to weeks, topics, modules, assignments, or other subsections of the instructor's choice. The instructor may choose which of the tasks is open in area 4 at any time (the default task).

Area 5 is by far the largest, and dominates most students' interactions with the system. Users' posts and polls go into this area, with the most recent sorted to the top by default (though filtering and sorting options are available). The scroll bar (not shown in Fig. 1) allows users to scroll through the entire semester of material in area 5. Students can create polls in one of two ways: by responding to an instructor prompt embedded in a task, or by choosing the Post tool in area 2.

\section{Posts and polls}

The CN tools we use most are the "posts" and "polls." Students and faculty can create posts that include text, Week 5 uploaded files and im- Do not forget Test 1! Monday morning, 9:00 AM in our usual classroom. ages, and links to external content. Each post can also include a title, and may open a new course discussion topic (which is subsequently appended to a list at the bottom of area 3). Poll questions may be in any of nine formats, including multiple choice, Likert scale, and short essay. The poll creator can set deadlines and control when other class members can see the results.

Once a post or poll has been created, other users (and the original poster) can "like" it, and can add "reflections" beneath it. Sub-reflections and likes of reflections are also supported. The system lists those users who have "liked" a post, and a user can click on the name of a fellow user in this list. This will launch a new browser window containing that user's profile and all of that user's posts and polls in the class. It will also display a button offering the opportunity to "follow" that user.

\section{The task tool}

Unlike posts and polls, only faculty can create tasks. The creation tool is similar to the post tool, with several added features. Tasks can include much more sophisticated formatting than posts, including HTML code, mathematical typesetting, special characters, lists, tables, and "SmartLinks." During task creation, an instructor may link some of the text to a variety of actions, such as "prompt students to create a post" or "show students a poll." This capability can be used to support assignments (or extra credit) and may be connected to the $\mathrm{CN}$ grade book. More than a dozen options are available. Fig. 2 shows an example from a course taught by AG in Fall 2014.

\section{Anar seeds}

Students' actions within CN earn "Anar Seeds" (pomegranate seeds). Actions include posting, creating a poll or reflection, liking an-
For lab, as always, you need to download and read the procedure and worksheet, and complete the prelabassignment.

We are starting our study of energy this week. Did you know that $E=m c^{2}$, probably the most famous equation in all of science, was first published 109 years ago this Saturday?

You are always encouraged to post questions (show all 2 course submissions) you have about the stuff we've been learning. Also, please reflect on your classmates' questions if you have answers.

Fig. 2. A "task" set up by the instructor (AG). Items in blue are "SmartLinks" providing linked to lab handouts, online content, and the post creation tool.

other student's post, completing a poll, etc. The instructor can set the number of seeds awarded for each action, the minimum post length, the maximum number earned for each action per day and per week. This system assures that students cannot earn large numbers of seeds without sustained effort. We view these seeds 
as "micropoints" and have experimented with offering a small reward in extra credit for earning a substantial number. It is clear from our conversations with students that they are motivated to earn seeds, and preliminary studies show that most will continue to earn seeds even after they have earned the maximum extra credit. $^{13}$

\section{Early results}

After two semesters use at IUPUI, we can report several encouraging results, both at the individual student level, and averaged over many users. Student participation is robust. In both semesters, a class of $\sim 150$ students created over 3000 posts, polls, and reflections. We also have preliminary evidence that female students use $\mathrm{CN}$ more than their male counterparts, see Table I. Combining data for the two semesters, we find the difference to be statistically significant with moderate effect size ( $p=0.022$, Cohen's $d=0.35$ ). This suggests that $\mathrm{CN}$ may provide female students additional benefits, e.g., in the creation of support networks.

Table I. Male and female students' average anar seeds earned \pm standard error of the mean. $\mathrm{N}$ is the number of students completing the course.

\begin{tabular}{|c|c|c|c|c|}
\hline & \multicolumn{2}{|c|}{ Male } & \multicolumn{2}{c|}{ Female } \\
\hline & Seeds & $\mathbf{N}$ & Seeds & $\mathbf{N}$ \\
\hline $\mathbf{2 0 1 4}$ & $335 \pm 18$ & 105 & $407 \pm 21$ & 31 \\
\hline $\mathbf{2 0 1 5}$ & $317 \pm 22$ & 99 & $380 \pm 42$ & 30 \\
\hline
\end{tabular}

Some of the posts students have created have been extraordinary! They include purely academic content, social support, and administrative information (there is no need to say "it's in the syllabus," the students tell each other!).

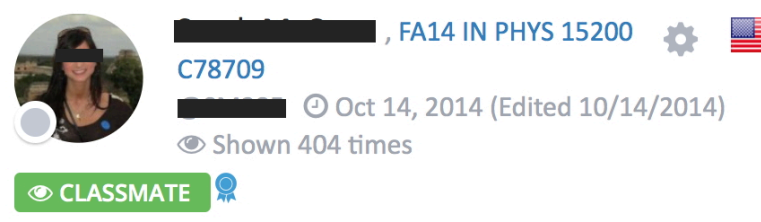

\section{Hawking Radiation Recreated In A Laboratory}

A researcher claims to have produced a simulation of Hawking radiation, which if true will give physicists the chance to test one of Stephen Hawking's most significant predictions. Thought it was pretty neat! http://www. iflscience.com/physics/laboratory-madehawking-radiation
Fig. 3. A student post on a physics topic not directly covered in the course

Fig. 3 shows a portion of a student post we would consider to be "academic." This was not an assignment of any kind. The student decided on her own to share this with the class.

A reflection we would consider "social" in nature read

i actually dropped this class last semester (bad decision) because i thought i wasn't smart enough but this cn networking helped me realize that $i$ shouldn't of done that because i realized that lots of people were in my shoes..... just try your hardest and you won't let yourself down!

While this has no direct physics content, its value to other students is clear, and it exemplifies one of the benefits of giving students an opportunity to communicate with one another.

Perhaps the most extraordinary posts came from a student who created three "experiments" that he performed on his own, one at home, and two at the gym. In each case, he included a brief write-up including predictions and analysis, plus photographic and video documentation of the experiment. In essence, he created three additional labs with multimedia reports. One such post, in which the student designed and performed a statics experiment, is illustrated in Fig. 4.

Readers will surely wish to know how whether use of $\mathrm{CN}$ leads directly to improved student outcomes. This is a complex question, which we are working to answer. Our early results do show clear correlations between $\mathrm{CN}$ use and increased homework scores, but we cannot demonstrate a causal relationship. ${ }^{14}$

\section{Conclusions}

CourseNetworking is a freely available social media tool designed to support learning and collaboration at the college level. CN places student work in a primary position on the page, provides a variety of tools that students like, and provides a real-time reward system for student participation. As a result, CN provides an online environment that supports engage- 
ment with the course far beyond what is typically accomplished with a traditional LMS. We have used $\mathrm{CN}$ in two semesters of calculus- based mechanics, and consider it a promising tool.

\section{FA14 IN PHYS 15200 C78709 5 on Nov 18, 2014 (Edited 11/18/2014) How much weight can you put on the end of a $20 \mathrm{~kg}$ Weight Bar?}

Using statics I setup the torque equation to equal 0 and solved for mass. My calculations (as shown in the image) said $22.9 \mathrm{~kg}$ at $.5 \mathrm{~m}$ from the pivot point. As shown in the video I slid a $20 \mathrm{~kg}$ weight on the end of the sleeve. The bar didn't raise on the end. I then balanced a $2.2 \mathrm{~kg}$ weight on top $(22.2 \mathrm{~kg}$ total now) and the bar began to rotate on the other side. I had to guess my .5 meters. For a rough experiment with many variables involved this came out pretty close!
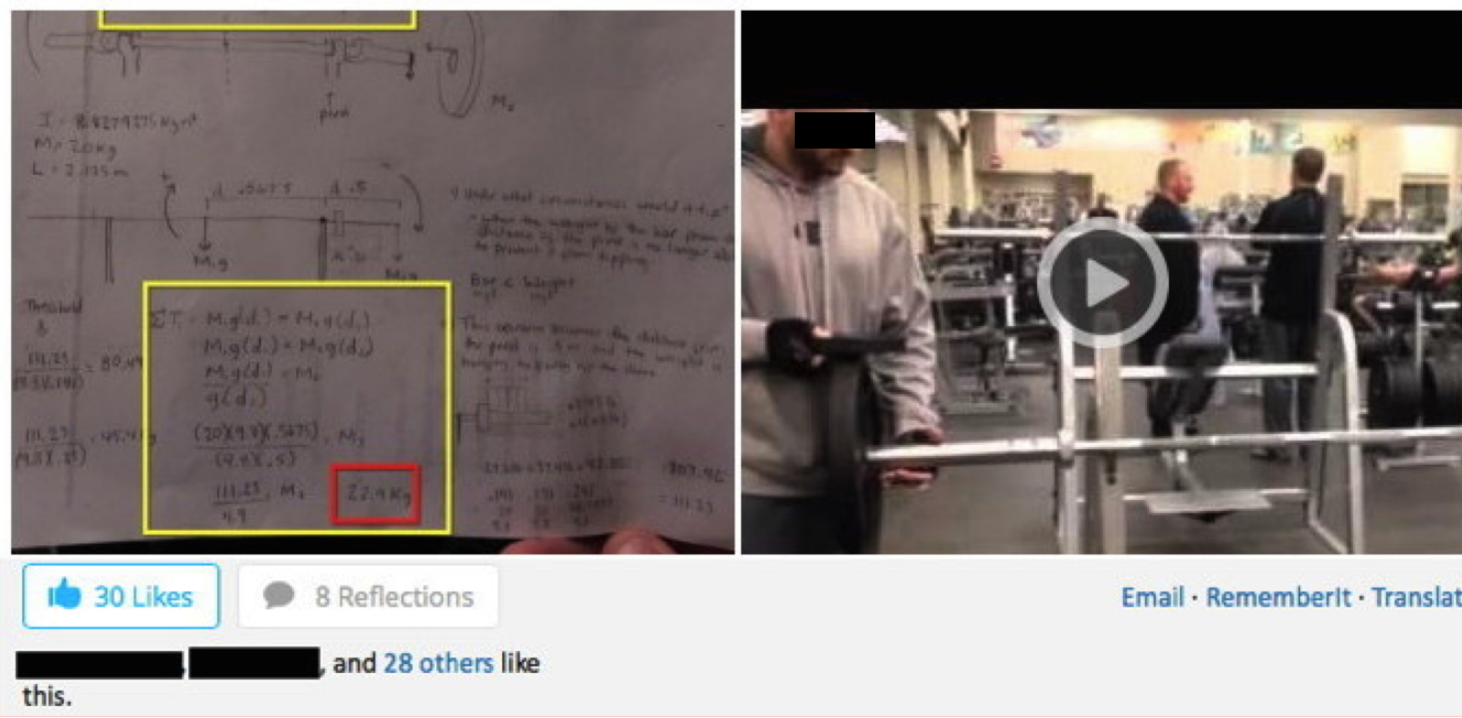

Email - Rememberlt - Translate

Fig. 4. A student post that asks, and answers, a statics question. A click on the area the lower left opens a .pdf file showing his calculations; a click on the area at the lower right opens a video of the student performing the experiment.

\section{References}

${ }^{1}$ E. Seymour, N. M. Hewitt, Talking About Leaving (Westview Press, Boulder, C0, 1997).

2 Mark J. Graham, Frederick, J. Byars-Winston, A., Hunter, A., Handelsman, J. "Increasing persistence of college students in STEM," Science 3411455 (2013).

${ }^{3}$ E. T. Pascarella, et al., "First-generation college students," J. Higher Ed. 75 (3), 249-284 (2004).

4 Pew Research Centers "Social media fact sheet," http://www.pewinternet.org/factsheets/social-networking-fact-sheet/ Downloaded 11/29/14.

${ }^{5}$ Kirschner, Paul A., and Karpinski, A. C., "Facebook ${ }^{\circledR}$ and academic performance," Computers in Human Behavior 26, 1237-1245 (2010).

${ }^{6}$ Junco, R., and Cotten, S.R., "No A 4 U: The relationship between multitasking and academic performance," Computers \& Education 59, 505514 (2012). 
${ }^{7}$ Gregory, Peter, Gregory, K. and Eddy, E. "The instructional network: Using Facebook to enhance undergraduate mathematics instruction," J. Computers in Math and Sci. Teaching 33 (1), 526 (2014).

${ }^{8}$ Author's note: This and other screen captures have been modified slightly to show the most salient details in minimum space.

${ }^{9}$ Learning Tools Interoperability is described at https://www.imsglobal.org/activity/learningtools-interoperability

10 The "Sharable Content Object Reference Model" is described at http://adlnet.gov/adlresearch/scorm/

${ }^{11}$ http://www.thecn.com/features

12 https://www.youtube.com/user/Course Networking

${ }^{13} \mathrm{R}$. Lindell, et al., "A new way to measure student engagement," AAPT Winter Meeting, 2015, San Diego, CA.

${ }^{14}$ A. Gavrin and R. Lindell, "Students' coursebased social media participation is positively correlated with homework effort," AAPT Phys. Ed. Res. Conf, Sacramento, CA, 2016. 